\title{
Telas e janelas, molduras das imagens*
}

"As idélas escritas neste texto tiveram origem naquelas ouvidas no curso "Poética da intertextualidạde", ministrado na Escola de Comunicações e Artes da Universidade de Săo Paulo (primeiro semestre de 1998) pelo Prof. Dr. Eduardo Peñuela Cañizal. A ele nosso reconhecimentó pela inspiração de suas palavras, que motivaram as nossas.

Rosana de Lima SoARES

Escola de Comunicações e Artes/USP 


\section{Resumo}

Partindo da idéia de escuridão como moldura fantasmática a envolver os devaneios e a imaginação do espectador, propomos refletir sobre as imagens geradas pelo cinema a partir da dupla articulação que engendram: enquanto telas, lembram espelhos que devolvem ao espectador imagens de si mesmo (ainda que não sejam puro reflexo), remetendo ao interior; enquanto janelas, evocam espaços de passagem e de abertura para o espectador que as contempla como um outro, remetendo ao exterior. Para além dessa dualidade aparentemente simplista, é no jogo entre dentro e fora - e na complexa relação intercambiante que estes dois termos estabelecem - que gostaríamos de situar nossa reflexão.

\section{Palavras-chave}

cinema, linguagem, imagem, molduras, interior/exterior

\section{Abstract}

From the idea of darkness as a frame that involves the dreams and the imagination of cinema viewers, this article approaches cinema images from a double articulation: as screens that reflect interior and static images, and as windows that open to an exterior world full of movement. The article intends to question this dualistic viewpoint, pointing out some of the complex relations that can be established between the inside/outside game performed by images.

\section{Key words}

cinema, language, image, frames, inside/outside 
Porque cremos que a visão se faz em nós pelo fora e, simultaneamente, se faz de nós para fora, olhar é, ao mesmo tempo, sair de si e trazer o mundo para dentro de si. Marilena Chauí

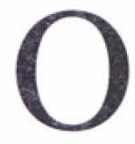

título escolhido para este artigo - Telas e janelas, molduras das imagens - já diz muito sobre ele. Trata-se de conceitos tomados em sua articulação discursiva, colocados como significantes soltos mas ao mesmo tempo encadeados. "A nuvem da linguagem faz escrita", já dissera Lacan em seus Escritos (1998). A imagem de uma nuvem - e nuvem de linguagem - evoca aquela do nosso título: palavras flutuantes mas consistentes de uma materialidade que enseja significações e, ao fazê-lo, demarca molduras, imagens em profusão a pulsar - abrir e fechar, revelar e esconder - as viagens e paragens das imagens no cinema.

O escurinho do cinema já foi falado por muitos, em prosa e verso. Retomamos neste artigo a escuridão como moldura fantasmática a envolver os fantasmas/fantasias de cada espectador, além daqueles do próprio diretor, que transparecem na opacidade da tela. De fato, poderíamos associar a moldura de uma tela (seja de pintura ou de cinema) com a opacidade - ela apenas nos devolve uma imagem que já é passado, ainda que na pintura esta imagem seja estática e, no cinema, movimento - e a moldura de uma janela com a transparência - ela nos abre para o mundo, apresentando-nos sua realidade. Assim como nas palavras, opacidade e transparência alternam-se para ora velar, ora revelar (ou re-velar, velando de novo) um suposto mundo interior/exterior, seja ele passado ou presente.

Mas se quisermos pensar a partir de uma visada teórica que não divide o mundo da linguagem (seja ela verbal ou visual), esta questão precisa ser problematizada para chegarmos à máxima: não se trata de reconhecer o mundo $e$ a linguagem que o traduziria, fa- 
zendo a ponte entre a interioridade do sujeito e a exterioridade do mundo, mas de afirmar: o mundo é linguagem. Podemos nos perguntar então: onde estaria o "lado de dentro", esboçado pela tela, e o "lado de fora" que a janela representaria?

Em relação às imagens, quem melhor expressa esse jogo de dentro e fora das telas e janelas é o pintor René Magritte. O quadro O sorriso do diabo (1966), por exemplo, traz desenhado o buraco de uma fechadura que se abre para uma paisagem do outro lado. Só que do outro lado encontra-se também a chave que abriria aquela porta, como a nos perguntar: onde é dentro e onde é fora? Ainda em Magritte, vemos um recorrente jogo de permutações entre a tela fechada do quadro e a janela que abre para o mundo. Muitas vezes sua pintura aponta para a fragilidade dessa divisão interior/exterior e a janela converte-se, ela mesma, em quadro que está sendo pintado.

Em A condição humana (1934), por exemplo, o pintor mostra uma determinada paisagem externa como se estivesse sendo olhada de dentro de um ambiente por alguém que a vislumbra por uma janela, mas cuja moldura é na verdade um cavalete de pintura. Há ainda uma outra versão de $A$ condição humana (1935) em que realidade e reprodução misturam-se e confundem-se a tal ponto que não podemos mais estabelecer os limites entre a vista do mar e a imagem no cavalete.

Outro artista que subverteu os limites entre o dentro e o fora foi o cineasta Luis Buñuel em seu jogo de símbolos' indefinidos e enigmas. No filme Lage d'or (1930), há uma sequiência em que vemos uma penteadeira - o espelho e a base onde se vislumbram objetos femininos: flores, perfumes, jóias. Uma mulher se encaminha para olhar-se no espelho. Deste pequeno gesto é que vem a ambigüidade que não se presta a interpretações simplistas: ao procurar nele sua imagem, eutra coisa que a mulher encontra. O espelho transforma-se em outro objeto (como nas telas-janelas de Magritte) e em vez de refletir o rosto da mulher esta desaparece para dar lugar a uma paisagem de nuvens agitadas por um forte vento.

A ruptura que advém dessas imagens aponta, uma vez mais, para a indistinção entre o interior e o exterior, seja em relação ao

1. Sobre esse conceito ver Peñuela Cañizal (1996). O simbolo seria aquele que não se deixa apreender facilmente, remetendo ao universo "do estranhamento, do enigmático, do relalo, da fragmentaçāo, da analogia, do desejo e das pulsōes". 
sujeito, seja em relação ao mundo que supostamente o circunda:

$O$ valor que o espelho tem na antiga crença de que haveria uma correspondência mágica entre a coisa e a cópia que ele faz dela é, de repente, deslocado: o espelho não copia o rosto da mulher que está na sua frente, mas sim uma outra coisa pertencente a um mundo que não cabe no quarto em que a protagonista foi confinada (Peñuela Cañizal, 1996).

Desaparece assim a oposição exterioridade/interioridade e tem lugar uma visão abrangente, e por isso difusa, das relações envolvidas na percepção das imagens, sejam aquelas que se passam na tela frente aos olhos do espectador, sejam aquelas que se passam no espelho frente aos olhos da protagonista.

Nesse movimento intercambiante, telas e janelas podem ser percebidas como molduras recobrindo/abrindo espaços. O termo moldura nos parece adequado tanto para indicar os limites-alcances da tela quanto os alcances-limites da janela. Moldura como aquilo que é, ao mesmo tempo, contorno e ruptura, como aquilo que demarca um campo e, ao fazê-lo, deixa de fora outras tantas imagens. Metáfora feliz, já que evoca inúmeras conexões e novas relações entre elas a possibilidade de perceber, por exemplo, que as letras, ao formar palavras, tornam-se elas próprias molduras; ou ainda, de pensar sobre o que resta no espaço vazio entre uma moldura e outra, seja de palavras ou imagens.

As inquietações concernentes aos espaços vazios entre as molduras encontram eco nas seguintes palavras:

(...) any meaning created or released through use of a framing device - and when I say frame I mean that which cuts colours and lights into images and noise into words - lies not so much on the inside of what has been isolated, but rather on the edges of what has thus been set aside (Wall, 1998, p. 5).

Pensada em sua forma usual, a moldura cria um espaço interno a ser preenchido para que possa "significar", o que muitas 
vezes faz com que se esqueça que a própria moldura é o resultado de uma interação entre os seus espaços internos e externos. Ou ainda: "L'espace intérieur étant ainsi indiqué, un autre espace, extérieur celui-ci, l'est du même coup: c'est de la bordure qu'il reçoit son statut d'extériorité" (Grupo $M$, s/d, p. 116).

Tal relação poderia ser pensada analogamente àquela estabelecida pelo signo lingüístico: um significante enunciado atesta a ausência do referente - só está ali porque aquilo que demarca, naquele momento e naquele lugar, não está, gerando espaços vazios. Se a moldura parece incluir algo, trazendo-o para dentro, é porque demarcou contornos, excluindo alguma outra coisa.

A palavra tela, relacionada no título à palavra moldura (talvez por seu caráter também demarcador) evoca múltiplas associações: a tela do pintor, a tela do cinema, a tela como bloqueio (para se evitar a queda) e suporte (caso se caia), a tela do computador, a tela da televisão, a tela como divisão (algo que separa). Em psicanálise, a tela $(\ll)$ constitui-se, para o sujeito, em uma espécie de marca única, suporte no qual vão se "pendurar" ou "amarrar" os nós que o caracterizam em sua singularidade. Tal singularidade, entretanto, ao mesmo tempc em que demarca uma distinção - o sujeito como pura diferença, por meio de traço unário que o caracteriza - repete-se para todos e cada um dos sujeitos, denotando a diferença de um "nada", de um vazio que constitui igualmente a todos. O inconsciente seria, assim, a absoluta igualdade na singularidade de cada um.

Nos dois extremos da tela estão, de um lado, o sujeito do inconsciente (\$) - sujeito barrado - e, de outro, o objeto pequeno $a-$ objeto causa do desejo. À representação $\$<>a$ dá-se o nome de "fantasma" (Lacan utiliza, em francês, a grafia fantasme, para diferenciá-la da palavra fantôme, ligada à idéia de "aparição"):

Atuando como elemento mediador, o fantasma situa-se na conjunção do inconsciente $e$ do objeto a (podemos adiantar: conjunção entre o simbólico e o imaginário). Lacan o designa na fórmula $\$<>\mathrm{a}$, onde o losango se le "desejo de", podendo ser lido no sentido retrógrado, introduzindo uma identidade que se funda sobre a nãoreciprocidade absoluta. O losango é o enquadramento do fantasma, a tela sobre a qual se projetam os objetos 
de desejo, fonte e origem do imaginário (Freitas, 1992a, p. 64).

O fantasma pertenceria à ordem do simbólico e não do imaginário, o que possibilita relacioná-lo a um espaço de escuridão como aquele evocado pelo cinema.

Já a palavra janela nos abre para outros significantes: os olhos como "janelas da alma" ou "espelhos do mundo" (cf. Chauí, 1988), as janelas que se abrem a paisagens paradisíacas, as janelas que permitem sair e ver o mundo, as janelas que trazem luminosidade para os interiores escuros (dos lugares ou de nós mesmos). A escuridão é, assim, moldura tanto da tela (do quadro, do cinema) como da janela (que deveria justamente trazer luz). E o que tal escuridão evocaria? A falta, o vazio, a hiância constituinte do sujeito. Tal vazio, entretanto, é de uma natureza outra: trata-se de uma brecha que deve permanecer enquanto tal, que deve permanecer vazia por ser estruturante.

No francês, fantasia e fantasma são termos que se confundem, especialmente quando se trata de seu uso em textos de Lacan e suas traduções. A palavra fantasia (fantaisie), entretanto, está mais ligada à idéia de imaginação (imaginaire, imagination). Às palavras fantasia e fantasma pode-se acrescentar, ainda, o significante fantasmagórico: relacionado à primeira delas, como aquilo que evoca medos ancestrais - e novamente pensamos na escuridão; relacionado à segunda palavra, remetendo ao fantasmagórico da própria realidade do sujeito, ela mesma um fantasma ( $\$<>a)$ já que marcada pela impossibilidade do sujeito barrado (falante/faltante) encontrar os objetos pequeno $a$ que estabeleceriam com ele uma relação de simetria.

Se falamos de fantasias e fantasmas, além dos conceitos acima esboçados - e quase como contradição - não poderíamos deixar de trazer o estranho a este universo. Estranho entendido aqui como aquilo que causa surpresa e inquietação; aquilo que desconcerta por remeter ao que é familiar, criando rupturas e novas possibilidades de significação: o ex-tranho, ou o que anteriormente estava nas entranhas e se torna externo. Um neologismo definido por Lacan - o ex-timo - pode apontar para uma relação com o 
estranho. Para escapar do subjetivismo apregoado pela psicologia, o autor afirma não haver separação entre o exterior (ex) e o interior (timo), os dois confundindo-se e completando-se inexoravelmente, como na figura topológica da banda de Moebius, um círculo retorcido no qual não há "dentro" e "fora": ao percorrê-lo, passa-se de um suposto dentro para um suposto fora, e vice-versa, alternadamente.

Freud, em um breve ensaio sobre estética - entendida não apenas como teoria da beleza mas também como teoria das qualidades do sentir -, cujo título em português é "O estranho"s/2 define-o como aquilo que, causando estranheza, ainda assim está ligado ao familiar: "(...) o estranho provém de algo familiar que foi reprimido (...) é aquela categoria do assustador que remete ao que é conhecido, de velho, e há muito familiar" (Freud, 1997: s/p). Buscando as origens da palavra em alemão, unheimlich. Freud relaciona-a ao "não-familiar", em oposição a heimlich:

Em geral, somos lembrados de que a palavra heimlich não deixa de ser ambígua, mas pertence a dois conjuntos de idéias que, sem serem contraditórias, ainda assim são muito diferentes: por um lado significa o que é familiar e agradável e, por outro, o que está oculto e se mantém fora da vista. Unheimlich é habitualmente usado, conforme aprendemos, apenas como o contrário do primeiro significado de heimlich, e não do segundo (Freud, 1997).

Avançando nessas considerações para relacioná-las ao conceito de fantasma, anteriormente apontado, chega-se a uma interessante definição de heimlich, proposta no texto de Freud:

Também se diz de um lugar livre da influência de fantasmas (...) familiar, amistoso, intimo (...); num sentido diferente, como afastado do conhecimento, inconsciente. Heimlich tem também o significado daquilo que é obscuro, inacessivel ao conhecimento (...) (Freud, 1997).

2. Em nota de rodapé, o tradutor destaca que o termo utilizado em inglês é uncanny (do alemão unheimlich, literalmente unhomely - "näo-familiar"). Entretanto, optou-se na tradução pela palavra estranho por ser uma das únicas que, em português, traz também o sentido de "fantástico", "misterioso", "sinistro". 
Assim pensado, o estranho pode ser caracterizado, em primeiro lugar, como aquilo que amedronta por ser algo reprimido que retorna - como o "saber que não se sabe" de que fala Lacan (1998) -, algo que, de acordo com Schelling, "deveria ter permanecido oculto mas veio à luz" (Freud, 1997). Dessa forma, "esse estranho não é nada novo ou alheio, porém algo que é familiar $e$ há muito estabelecido na mente, e que somente se alienou desta através do processo da repressâo" (Freud, 1997). Daí nosso ensejo em relacioná-lo a este texto e, assim fazendo, ao seu próprio conteúdo, evocando "o estranhamente familiar" dos surrealistas, que se apresenta quando a distinção entre imaginação e realidade é eliminada, ou quando o imaginário surge diante de nós na realidade, como "quando um simbolo assume as plenas funções da coisa que simboliza, e assim por diante" (Freud, 1997).

Retomando a imagem da moldura como provocadora de estranhezas, pode-se perguntar: como pensar um dentro e um fora em relação a ela? Qual seria o fora de uma moldura, já que ela está sempre a criar novas bordas? Estabelecer tal limite parece tão difícil quanto dizer qual o fora da escuridão, espaço do fantasmagórico e do estranho, convite ao sonho e ao medo, espaço mesmo da fantasia e do devaneio.

A escuridão como moldura é um convite ao imaginário produção de imagens, imaginação. Deslocamentos, como aqueles gerados nos filmes de Buñuel ou nas telas surrealistas de Dalí e Magritte, nos quais as coisas raramente são colocadas em seus lugares convencionais, como já apontamos anteriormente. O universo onírico não estaria, assim, nos sonhos, mas na realidade que nos circunda. "O mundo é sonho", diria o dramaturgo espanhol Calderón de La Barca. Basta saber olhar... e lá está o espanto.

De acordo com Freud, condensação e deslocamento seriam, nos sonhos, vestígios da maneira pela qual o inconsciente trabalha. Em termos linguísticos, pode-se relacionar a condensação à metáfora e o deslocamento à metonímia, ainda que com a ressalva de que nos estudos do Grupo $M$ o que Jakobson e Lacan chamam de metonímia é denominado sinédoque: generalizante, que vai do todo à parte, ou particularizante, tomando a parte pelo todo. A metáfora seria, de acordo com esta concepção, a combinação de duas sinédoques, uma generalizante e uma particularizante. 
Apesar de tal distinção, de Jakobson é importante destacar o duplo caráter atribuído ao signo linguístico. Ao desenvolver seu trabalho sobre a fonologia, Jakobson enfatiza duas operações fundamentais implicadas no ato de falar: a seleção de certas unidades lingüísticas do léxico comum e a combinação dessas unidades em unidades cada vez maiores. Em Jakobson, o eixo da seleção (ou paradigmático) é o eixo metafórico (vertical), no qual os termos são unidades in absentia. Este eixo está mais relacionado à língua como sistema, apresentando-se sincronicamente enquanto pontualidade no tempo. Nele estão colocados os significantes da língua. O eixo da combinação (ou sintagmático) é o eixo metonímico (horizontal), e seus termos são unidades in praesentia. O plano da combinação está mais ligado à fala, apresentando-se diacronicamente como sequencialidade. A ele está associada a ordem dos significados.

De forma simplificada, pode-se afirmar que a metáfora, enquanto figura de linguagem, é aquela em que um termo é substituído por outro, próximo a ele. Na metonímia, uma parte é tomada pelo todo, estabelecendo um movimento de continuidade. É nesse sentido que tais figuras estariam sendo colocadas nos dois eixos da linguagem (seleção e combinação). Notemos as relações de similaridade e contiguiidade, apontadas acima, como relativas, respectivamente, à metáfora e à metonímia, à condensação e ao deslocamento.

Uma aproximação aos sonhos, conforme proposta por Freud, torna-se possível, elucidando suas semelhanças e diferenças em relação a Jakobson. Discorrendo sobre as possibilidades de haver uma interpretação dos sonhos, Freud distingue dois casos operantes em que a pressão da censura do sujeito quanto ao conteúdo do sonho faz surgir associações aparentemente desconectadas.

No primeiro, a censura se volta apenas contra a ligação entre dois pensamentos que, separadamente, não suscitam objeção. Nesse caso, os dois pensamentos penetram sucessivamente na consciência; a ligação entre eles permanece oculta e, em seu lugar, ocorre-nos entre os dois uma ligação superficial em que, de outra maneira, nunca teríamos pensado (Freud, 1988, p. 486). 
Trata-se, nesse caso, do processo de deslocamento, que Lacan aproxima, em seus Escritos (1998), do conceito de metonímia de Jakobson.

Freud prossegue: "O segundo caso é aquele em que os dois pensamentos, por si só, são submetidos à censura por causa de seu conteúdo" (Freud, 1988, p. 487). Ao contrário do que ocorre no primeiro caso, neste

nenhum dos dois aparece em sua forma yerdadeira, mas apenas numa forma modificada que a substitui, e os dois pensamentos substitutos são escolhidos de maneira a possuírem uma associação superficial que reproduza o vínculo essencial que relaciona os dois pensamentos substituidos (Freud, 1988, p. 487).

Verifica-se um processo de condensação (sem negligenciar que nele está também implicado um desloçamento), associado por Lacan ao conceito de metáfora de Jakobson.

As operações de deslocamento e condensação dos sonhos são evocadas por estarem diretamente ligadas ao universo onírico propiciado pela moldura da escuridão. Entre luzes e sombras, sombras e escuridão, move-se o universo do fantástico da fantasia, do fantasmático do fantasma, do fantasmagóríco da própria realidade através da tela do sujeito - espelho e projeção, reflexo e transparência.

As idéias alinhavadas neste artigo o fazem de forma interrogativa, buscando articular alguns conceitos teóricos para avançarmos na reflexão sobre as relações entre as telas e as janelas como molduras da escuridão evocada pelas imagens do cinema. Por apresentar questões ainda abertas, encerramos o texto também com uma pergunta, que remete a tantas outras: o que se passa na margem das imagens das telas/janelas do cinema, movendo-se entre o sonho do sono e o sonho da vigília? O que está sendo incluído ao se estabelecer os contornos de suas molduras? Analogamente, o que se exclui desse quadro que demarca seus alcances?

Como possível resposta, evocamos as palavras poéticas de quem navega no mar de significações, que tão bem expressam as articulações que, fragilmente, tentamos estabelecer: 
Quero dizer, em suma, que navegar sobre o mar dos signos é, a cada instante, intuir que, sob a ondulação das frases feitas, vagueiam, em correntezas mais fundas, cardumes de outras palavras cuja irradiação poderá, às vezes, enturvar a enganosa transparência das superfícies. E que a única experiência que carrego para essa travessia é a de saber que as palavras, quando se ausentam, projetam, nas telas da memória, imagens espectrais de sua própria ausência (Peñuela Cañizal, 1987, p. 3).

A sobreposição de imagens presente nos filmes de Peter Greenaway talvez seja uma possibilidade de entrada nesse jogo de inclusões e exclusões. Cineasta que utiliza em profusão recursos tecnológicos em seus filmes, mas sempre implicados em uma narrativa complexa e instigante, Greenaway apresenta-nos um procedimento semelhante à concepção do computador ${ }^{3}$ : na tela que a nós se mostra, abrem-se sucessivamente inúmeras janelas, às vezes encobrindo umas às outras, às vezes com um fundo translúcido que deixa ao menos entrever o que está atrás. As telas sobrepostas de Greenaway, como a tela do computador, não distinguem entre textos verbais ou icônicos: apresentam todos os seus elementos como pura imagem. E convidam mais uma vez à pergunta sobre o jogo entre o dentro e o fora, sobre os contomos e os esboços das molduras telas e janelas - que nos remetem sempre a novas paisagens.

3. Os que trabalham com computador nầo se surpreenderăo ao perceber que não é por acaso que sua interface mais utilizada tenta o nome de Windows. 


\section{Bibliografia}

AUMONT, J. 1997. "De un marco al outro: el borde y la distancia". In: El ojo interminable. Cine y pintura. Madri: Paidós (Comunicación Cine, 78).

CHAUÍ, M.1988. "Janelas da alma, espelhos do mundo". In: NOVAES, A. (org.). O olhar. São Paulo: Companhia das Letras.

FREITAS, J. M. M. 1992a. Comunicação e psicanálise. São Paulo: Escuta, (Col. Ensaio).

1992b. Bemaldivida. São Paulo: Edusp (Col. Campi).

FREUD, S. 1975. "Jokes and their relation to the unconscious". In: Standard Edition. London: The Hogarth Press.

1988. A interpretação dos sonhos. Volume II. $2^{*}$ ed. Rio de Janeiro: Imago.

. 1997. "O estranho". Obras psicológicas completas de Sigmund Freud. Edição Standard Brasileira. Volume XVII. São Paulo: Imago.

GRUPO U. 1998. "Sémiotique et rhétorique du cadre". Texto distribuído no curso de PEÑUELA CAÑIZAL, Eduardo. Poética da intertextualidade. São Paulo: ECA/USP, $1^{\circ}$ semestre.

JURANVILLE, A. 1987. Lacan e a filosofia. Rio de Janeiro: Jorge Zahar.

KAUFMANN, P. (ed.).1996. Dicionário enciclopédico de psicanálise. O legado de Freud e Lacan. Rio de Janeiro: Jorge Zahar.

KRISTEVA, J. 1974. História da linguagem. Lisboa: Edições 70 (Col. Signos).

LACAN, J. 1990. Os quatro conceitos fundamentais da psicanálise. 4" ed. Rio de Janeiro: Jorge Zahar.

1998. Escritos. São Paulo: Jorge Zahar (Col. Campo Freudiano no Brasil).

LYOTARD, J.-F. 1990. O inumano: considerações sobre o tempo. Lisboa: Estampa (Col. Margens).

PEÑUELA CAÑIZAL, E. 1987. Surrealismo: rupturas expressivas. $2^{\prime}$ ed. São Paulo: Atual (Série Documentos).

. 1996. "Emblema e símbolo no texto fílmico". (mimeo). 
WALL, A. 1998. "On the edges of words and pictures". Texto apresentado no Seminário Avançado La parole comme image. L'image comme parole. São Paulo: ECA/USP, maio. 